\title{
THE WORLD AT THEIR FEET
}

These newcomers are making their mark in science across the disciplines.

From cutting the cost of solar electricity to reducing the risk of ovarian cancer, the 11 early- to mid-career scientists profiled here are emerging as leaders in their fields.

They stood out from among 500 scientists assessed using the power of the Nature Index and the League of Scholars Wholeof-Web (WoW) rankings. They are bringing fresh ideas in a range of disciplines, from cognitive neuroscience to geology, and condensed matter physics. Their initiative, curiosity and flexibility have given them an edge in a competitive research environment.
The analysis included active researchers who have published at least one paper in the 82 index journals in 2017, and whose first scientific paper appeared less than 20 years ago, with some even emerging on the scholarly scene in the past six years.

The profiled scientists have shown year-on-year citation growth, and scored exceptionally in the WoW ranking, which identifies the most influential researchers using an algorithm similar to Google's PageRank. It considers factors such as the quality of a scientist's output, links to industry, and co-authorship networks.

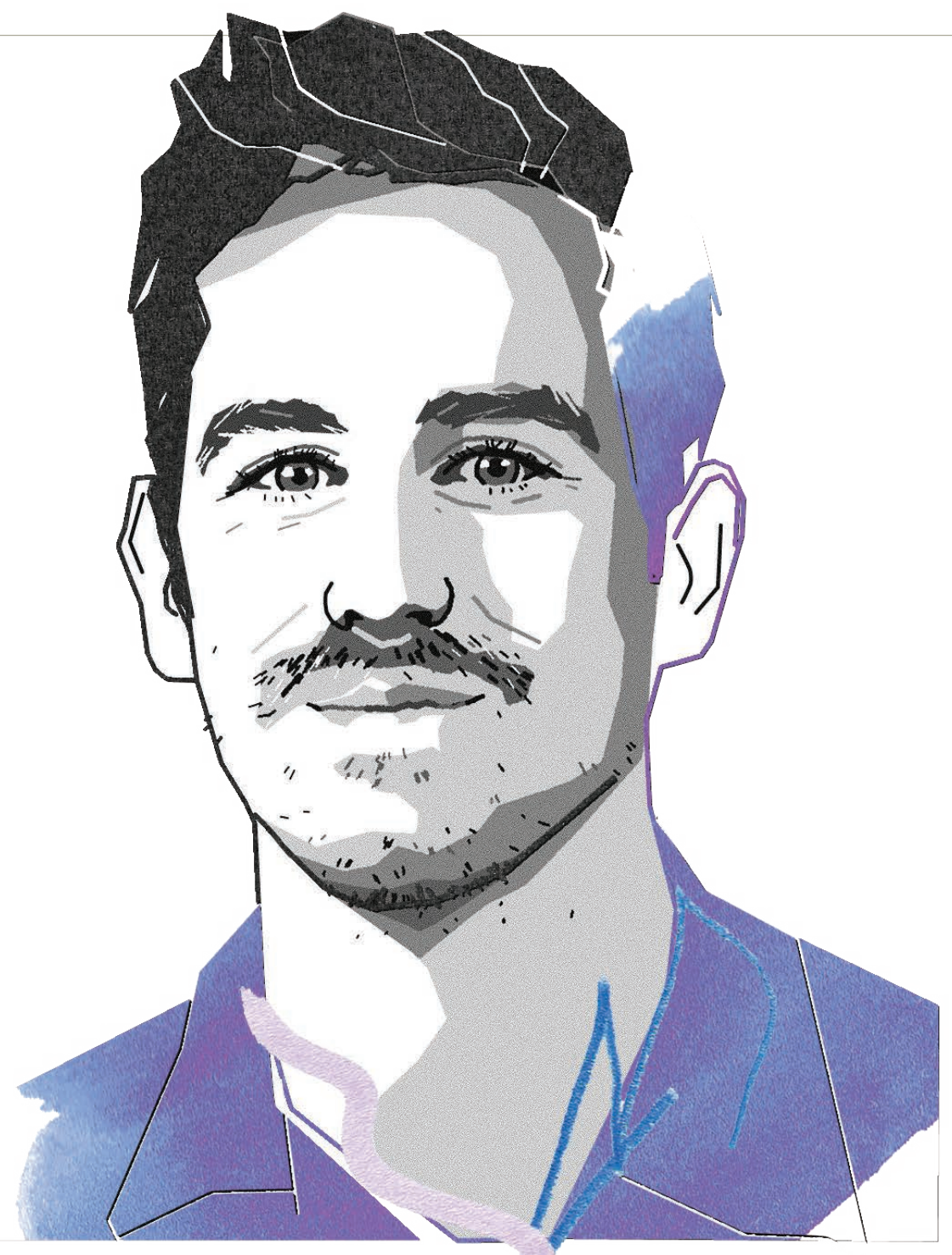

\section{RESEARCH RECORD}

Dane deQuilettes's publication history. Each dot represents one paper, with citation figures correct as of 3 August 2018. Red dots represent papers published in one of the 82 journals tracked by the Nature Index. Some dots overlap.

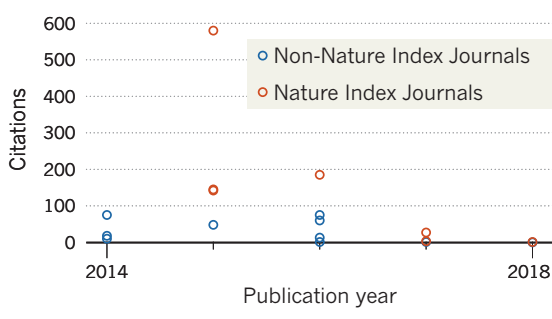

\begin{tabular}{|c|}
\hline DANE DEQUILETTES, 28 \\
\hline MASSACHUSETTSINSTITUTE OF TECHNOLOGY \\
\hline
\end{tabular}

\section{DEFECT DETECTIVE}

A chemist seeks the right material to bring cheap, solar electricity to those without access.

Materials scientist Dane deQuilettes hopes to help transform the world's energy systems, especially for people who don't have reliable access to electricity. The postdoc at MIT is using his expertise in the properties of promising materials called perovskites to make it happen.

The performance of perovskites in solar cells rivals conventional silicon, and they promise to be much cheaper to make. While costs of silicon solar cells, which supply $1.7 \%$ 
of the world's electricity, have come down, they are not likely to fall low enough to make an impact for the 1.2 billion people globally who don't have access to grid electricity.

GridEdge Solar is an MIT project, led by deQuilettes, to evaluate different lightweight, flexible photovoltaic materials, and, in a few years, build a pilot line to manufacture them. He thinks perovskites, which can be made into ink-like solutions and printed on rolls of material, similar to newsprint, are a strong contender. The project is funded by the Indian philanthropic organization Tata Trusts.

deQuilettes, who has a background in chemistry, started working on perovskites during his $\mathrm{PhD}$ at the University of Washington. Fascinated by their particular crystalline structure, he has studied how single misplaced atoms in perovskites can degrade their properties and inhibit their performance in a solar cell. Before his work, it wasn't clear why there was so much variation in the quality of perovskite solar cells. deQuilettes revealed the answer in the varying atomic alignment in different regions of the crystalline materials. "Once we understood where the defects were, we could work on a design strategy to remove them and make the performance of the device more uniform," he says.

"I'm interested in the fundamental physics of how light interacts with materials, but I always come back to, 'What's the purpose?"' says deQuilettes. KATHERINE BOURZAC

\section{HEARTFELT REASONER}

\section{A cognitive neuroscientist reveals} how the body moves the mind.

Sarah Garfinkel studies how beats of the heart, and our awareness of its rhythms, can influence everything from anxiety levels and emotional learning, to sleep quality and racial bias. She's now one of the world's foremost experts on the health consequences of 'interoception', the felt sense of one's internal organ activities.

As a postdoc at the University of Michigan, Garfinkel studied memory recall among veterans of the Iraq and Afghanistan wars who were suffering from post-traumatic stress disorder. Her study focussed mostly on the brain, but a curious observation led Garfinkel to wonder about the role the heart might play in emotional processing. Why was it that the heartbeats of some veterans remained steady while in the brain scanner reliving their traumatic experiences, whereas the hearts of others raced frantically?

Working with Hugo Critchley, a neuropsychiatrist at the Brighton and Sussex Medical School, she revealed a disconnect between how good people think they are at detecting their own heartbeats and their true

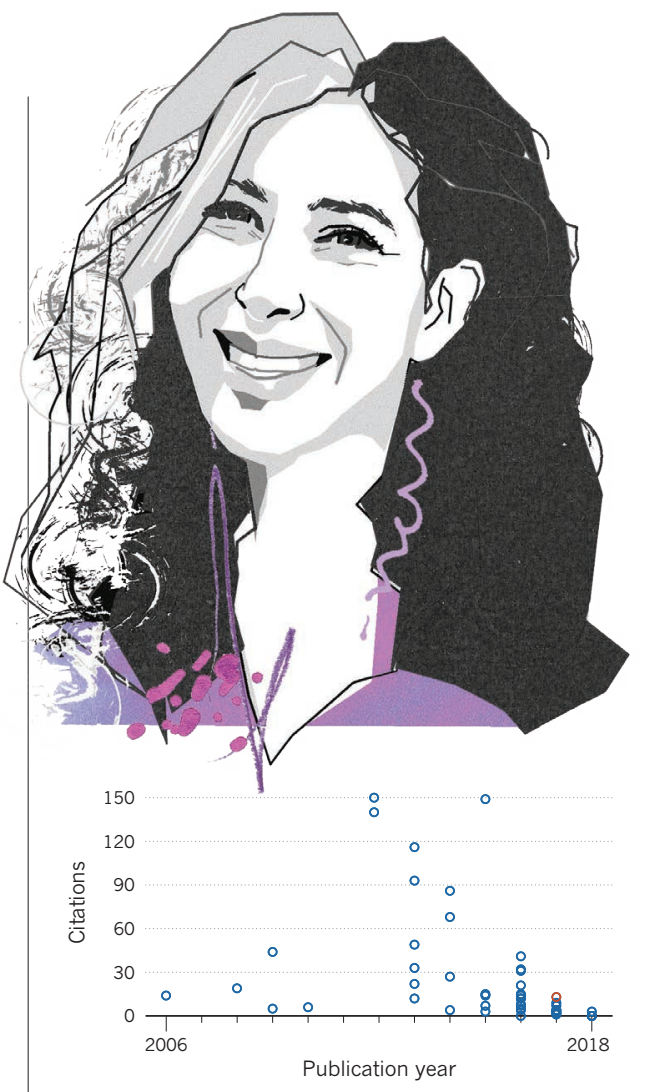

SARAHGARFINKEL, 38

BRIGHTONANDSUSSEXMEDICALSCHOOL

accuracy. Garfinkel then showed why that incongruence matters, reporting in 2016 that the less people with autism knew their own hearts, the greater their anxiety.

In another study, she and Critchley found that poor interoceptive awareness among people with depression or anxiety was associated with deficient sleep quality. "This now gives us a target for intervention," Garfinkel says. "We want to train people to have better precision over their bodily signals."

Garfinkel is now co-leading one of the first clinical trials of an interoception-directed therapy, evaluating whether a computer training module can help people with autism become more in tune with their heartbeats and thereby reduce anxiety.

Critchley says psychologists had been aware of interoception for more than a century, but its clinical importance had largely been overlooked until Garfinkel's work. "She reinvigorated this whole field," he says. ELIE DOLGIN

\section{ELECTRON MICROSCOPIST}

A condensed-matter physicist peers deep into materials for industrial applications.

Binghui Ge made his mark with an answer to Richard Feynman's 1959 challenge: "Is there no way to make the electron microscope more powerful?” Invented in 1931, transmission electron microscopy (TEM) vastly improved the resolution of conventional optical microscopes by using a beam of electrons, instead of light, to reveal nanometresized structural features. But Feynman urged researchers to improve the resolution by a hundred times. Drawing on imaging theory, Ge and a team at the Chinese Academy of Sciences's Institute of Physics developed a method for obtaining structural information less than a nanometre in size, using conventional TEM. They provided the first analytical expression of image distortions that arise in samples of greater thickness and used that to observe individual atoms.

Ge has moved on to the application of TEM to reveal the microstructures of catalysts and thermoelectric materials in unprecedented detail. Recently, he has been exploring the microstructure of thermoelectric materials at multiple scales, with a view to improving their efficiency in heating, cooling and generating power. These materials could be used to convert the wasted two-thirds of heat produced by vehicle engines to electricity.

Ge wants to explore cryo-electron microscopy, a TEM method allowing scientists to image three-dimensional biological molecules without destroying samples. Ge wants to know whether this can improve imaging of non-biological materials that are also susceptible to beam damage, such as metalorganic frameworks, widely used in catalysts. CATHERINE ARMITAGE

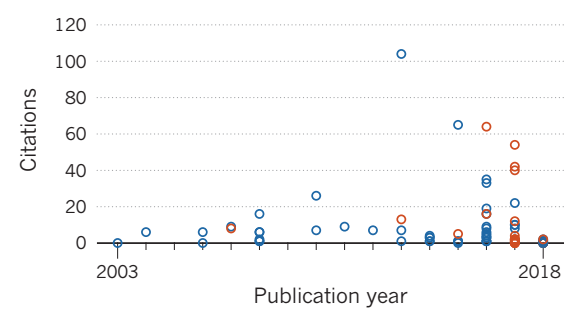

BINGHUIGE, 40

INSTITUTE OF PHYSICS, CHINESE ACADEMY OF SCIENCES

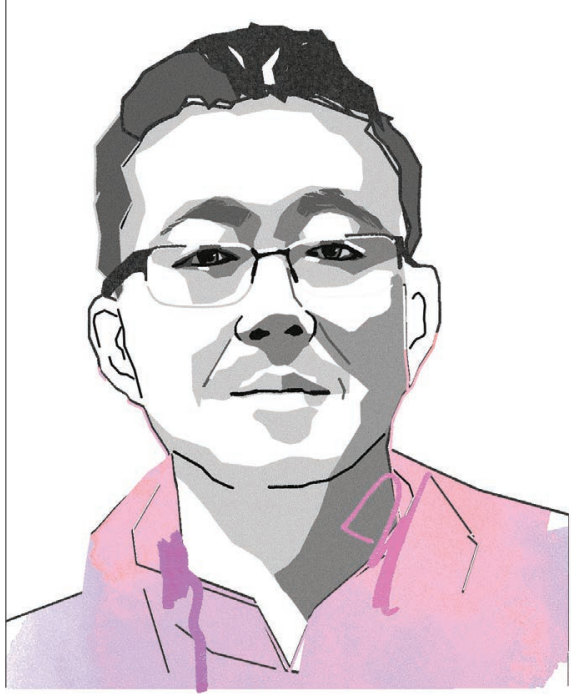




\section{FROST SURVEYOR}

A physical geographer digs deep

in frozen soils to fill gaps in maps.

To Gustaf Hugelius, white space on a map presents a challenge. The modern-day explorer, who as a boy hiked every summer in northern Scandinavia, looks for peatland and permafrost areas of the Arctic and subArctic regions where soils have not been analysed. The gaps in the maps have taken him as far as Siberia, Greenland, and northern Canada.

Arctic peatland and permafrost represent $25 \%$ of the Earth's carbon sink. Global warming is expected to thaw these frozen grounds, releasing carbon dioxide and methane into the atmosphere and accelerating climate change. Yet their potentially crucial role in the carbon-climate feedback cycle is poorly understood, partly due to large gaps in the data.

Hugelius has pioneered the use of highresolution satellite imagery, calibrated with field samples, to show that northern soils, due to seasonal freezing and thawing, are far more variable and complex in composition than the comparatively simple 'backyard' soil types used in climate modelling. Reflecting the diversity in soil composition and, correspondingly, in the decomposition process that releases greenhouse gases, could improve the accuracy of climate models.

The field research is "very demanding", he says. There are permits to secure; there are the logistics of getting people, equipment and supplies to some of the world's most remote regions for long stays; and the sheer difficulty of drilling into ice-hard ground for samples. Not to mention the polar bear risk. "You need to be aware of the bears, both for their safety and for ours," he says.

Poor data sharing has long been a problem for soil research, he says. As manager of the Northern Circumpolar Soil Carbon Database, a dataset of organic carbon stored in soils of the region he studies, Hugelius is helping to fix that, also working with climate modellers so they can better account for uncertainty in the models. CA

\section{READY-TO-WEAR DESIGNER}

\section{A system engineer develops stick-on} sensors to monitor health.

One day, stretchy sensors applied to the skin, like temporary tattoos, will monitor vital signs, predicts Jaemin Kim. If things go according to his plan, sophisticated and squishy electronics will give robots a sense of touch.

Kim, a system engineer from South Korea, became interested in wearable electronics

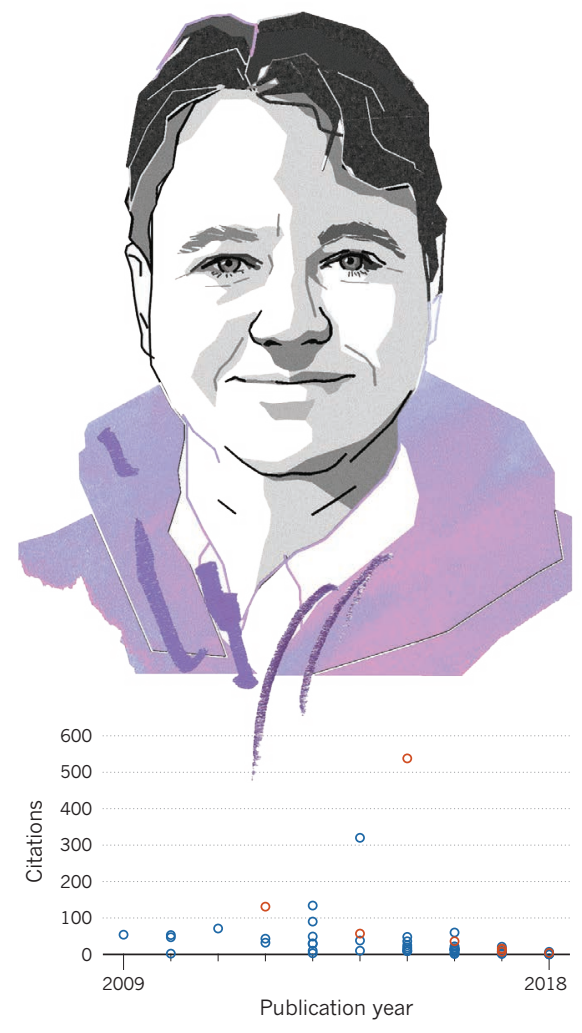

GUSTAF HUGELIUS, 38

STOCKHOLMUNIVERSITY
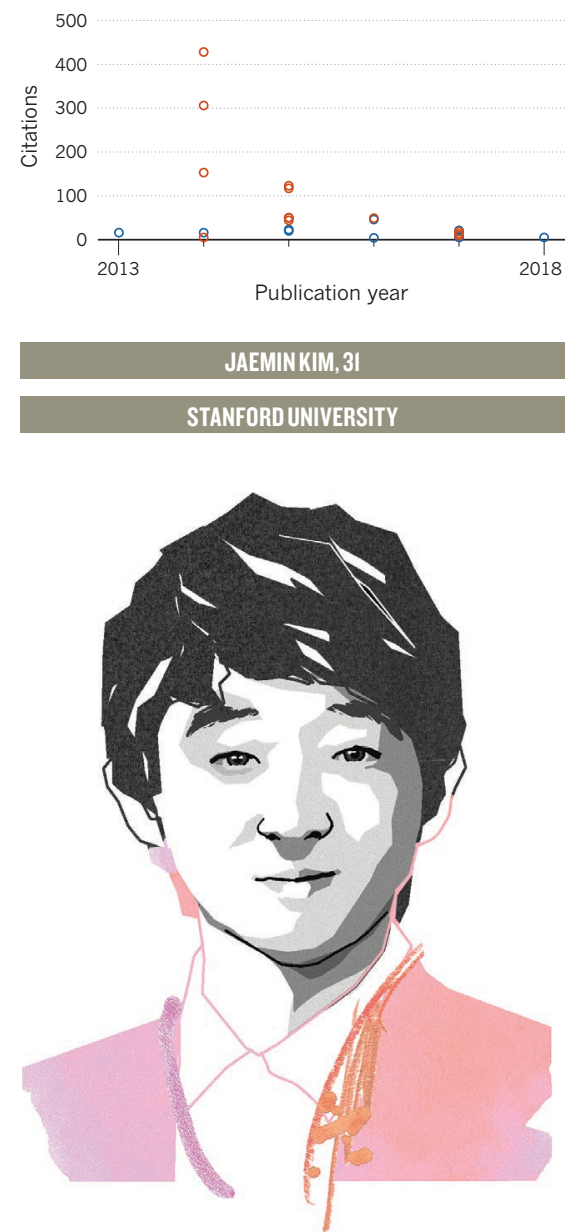

during his master's degree at the Korea Advanced Institute of Science and Technology in Daejeon. "I tried to measure emotion by measuring goosebumps," he says. The best way to sense the changes, he learned, was not with typical, rigid electronics, but pliable ones that move with the skin.

Throughout his PhD at Seoul National University, Kim developed sensors and systems for stretchy devices, including a sticker-like heart monitor that uses a printed heart-shaped display to tell the wearer whether her electrocardiogram is normal (red heart) or unhealthy (blue).

He has worked on a soft, curved image sensor that could one day become the basis for a retinal implant for blind people. But, he says, a lot of difficult engineering work is needed to make these promising devices practical.

The flexible electronics in his publications have to be attached to bulky external electronics and power sources to work.

In November 2017, he moved to California to work as a postdoctoral researcher at Stanford University with Zhenan Bao, one of the leading chemists designing intrinsically stretchy electronic materials. At the Bao lab, Kim is focussing on using these materials to make standalone medical and touch sensors that don't have to be tethered to a bulky microcontroller to analyse the data they gather.

Kim says he's torn about whether to continue in academia or take an industry role. He wants to see this research translated to products. "I want to make something that works for everyone," he says. KB

\section{MINI-MOLECULEMANIPULATOR}

An organic chemist creates hydrogels made of cost-effective, self-assembling proteins.

Antimicrobial peptides, made of chains of amino acids, are the body's first line of defence against invading pathogens. These proteins have the geometric quality of chirality, which means they cannot be overlaid on their mirror images, just as a left-handed glove doesn't fit on a right hand.

Their chirality also determines their biological activity - a quality that pharmaceutical manufacturers have long utilized to create drugs with sought-after properties. The heartburn pill, Nexium, for example, is made from a left-handed molecule. Its predecessor drug, Prilosec, also made by AstraZeneca, included the left and right hands of the molecule pair.

These molecules generally consist of long strings of hundreds of amino acids. Organic chemist, Silvia Marchesan, of the University of Trieste in Italy, has a more refined and cost-effective approach. She works with 


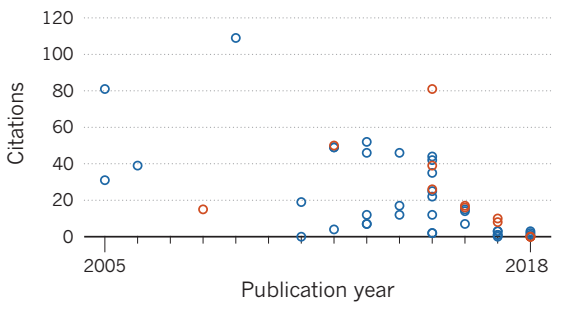

SILVIA MARCHESAN, 39 UNIVERSITY OF TRIESTE

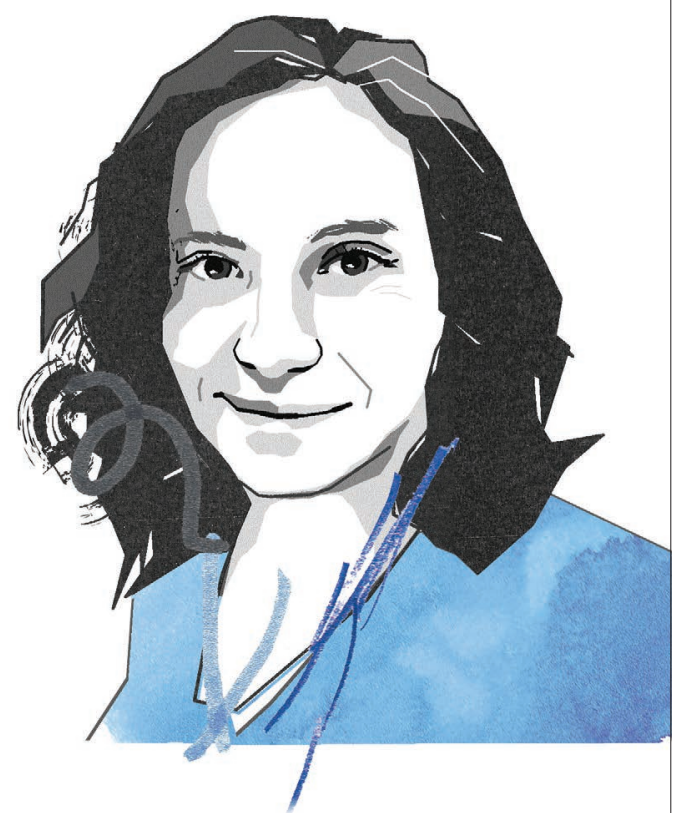

short peptides, only three amino acids long, and switches the chirality of the individual amino acids. "It's like putting a right-hand finger on a left hand to see what kind of hand we get, and how this new hand behaves differently," she says.

Marchesan has used this technique to make tripeptides that self-assemble into water-based gels that have intrinsic antimicrobial properties and are biocompatible. The supramolecular structure of the hydrogels allows the potential to switch functions on and off, making them useful as enzyme substitutes, scaffolding in the repair of body tissue, and for the sustained delivery of drugs.

In 2013, Marchesan co-authored a paper, which described combining the self-assembling tripeptides with a common antibiotic. The resulting hydrogel continuously released the drug over six days.

A paper that made the August 2018 cover of Chem describes why Marchesan's tweaked tripeptides behave differently from their real-world analogues and how the process holds consistent across the scale from single molecule to macroscopic hydrogels, which is important for large-scale production. The next step, says Marchesan, is to refine the lab process into one that can be scaled up cheaply and sustainably. CA

\section{CANCER SLEUTH}

A marine biologist turns molecular epidemiologist to tackle ovarian cancer risk.

It's hard to study marine biology from landlocked Vermont. So, as an undergraduate, Melissa Merritt left to spend a semester investigating the reproductive abilities of corals along the Great Barrier Reef in northeast Australia. Within a few years, though, Merritt had to give up ocean studies due to problems with sea sickness, and went into cancer research. Her grandmother had ovarian cancer and Merritt decided to devote herself to elucidating risk factors and genetic drivers of the gynaecological disease.

For her $\mathrm{PhD}$ and postdocs, Merritt trained in cancer epidemiology and molecular biology at institutions across Australia, the

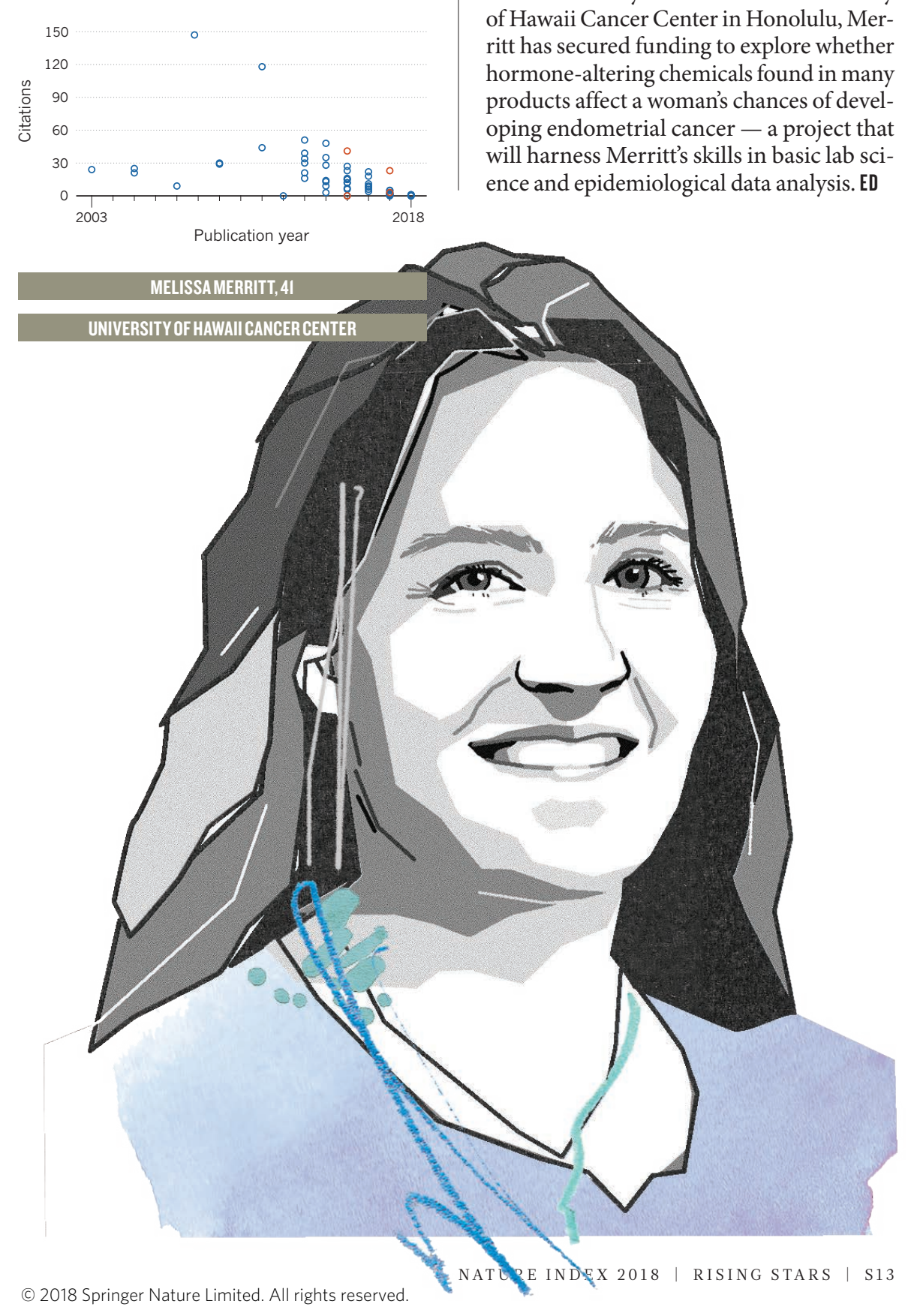

United States and the United Kingdom - gaining experience and a dual scientific background that made her "very adept at formulating important research questions", says molecular epidemiologist Marc Gunter, a former mentor from Imperial College London.

In 2015, for example, Merritt helped develop a methodological approach for evaluating the risk of dietary factors in cancer. It is now being used to study the links between foods and tumours of all kinds, and has also shown that coffee intake helps lower a woman's risk of developing endometrial cancer.

In what Merritt considers her most "significant finding", she showed in a recent study that women with locally invasive ovarian cancer have approximately a 30\% lower risk of dying from the disease if, after their diagnosis, they take aspirin or a nonsteroidal anti-inflammatory drug like ibuprofen.

Now a faculty member of the University of Hawaii Cancer Center in Honolulu, Merritt has secured funding to explore whether hormone-altering chemicals found in many products affect a woman's chances of develin basic lab science and epidemiological data analysis. ED 


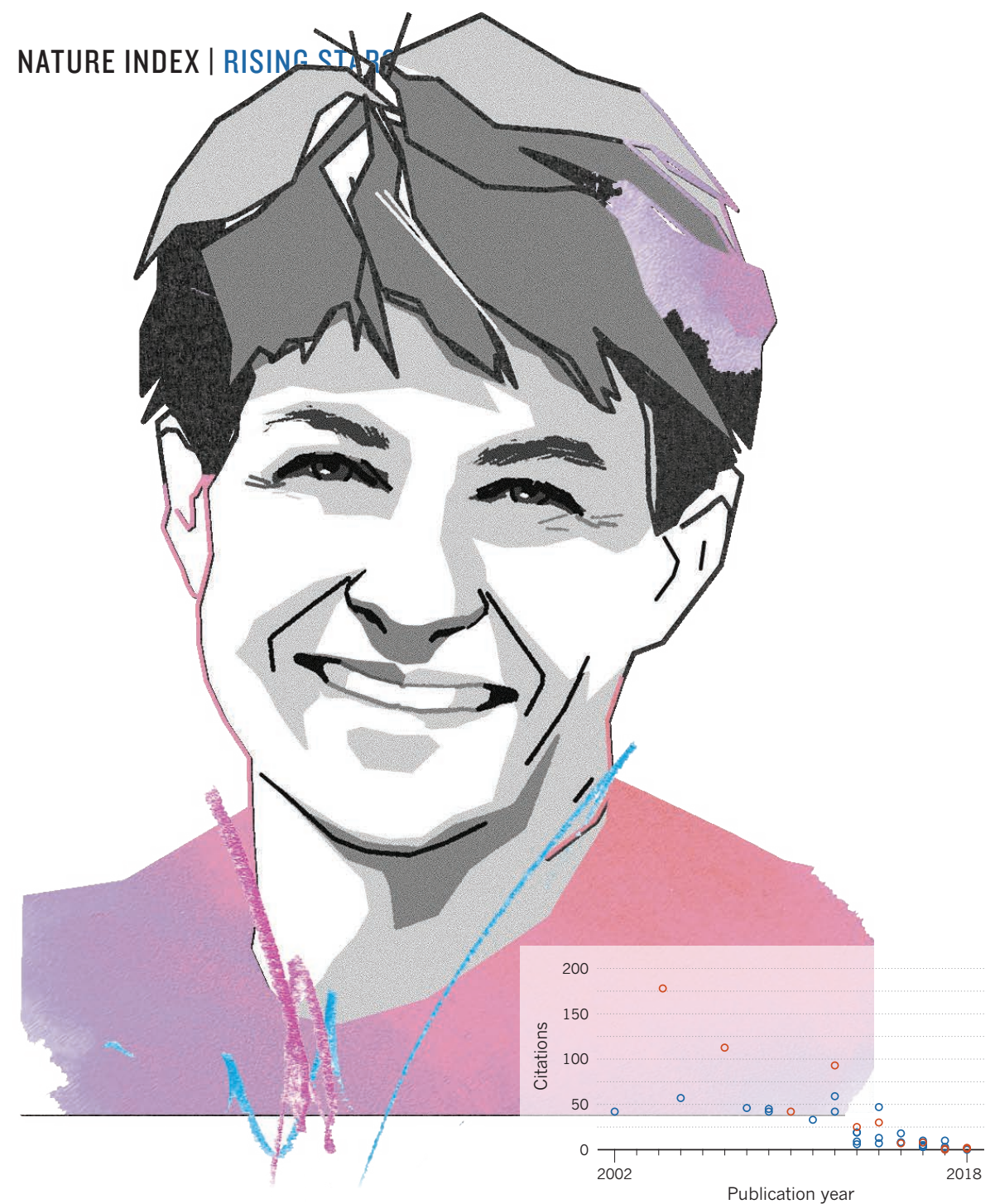

\section{CLIMATE ROCKER}

A geologist studies how changes in climate wear away mountains and riverbeds.

By geological standards, the timescales that Taylor Schildgen studies are short. She is trying to determine how climate transforms the Earth's surface over thousands of years. Her work uses a new technique to date landforms, by measuring the presence of rare isotopes known as cosmogenic nuclides. The proportion of these isotopes in rock samples allows geologists to estimate their age and rate of change over millennia.

In 2017, Schildgen published a paper, with postdoc, Stefanie Tofelde, considering the influence of global climate variations on river terraces in the Argentinian Andes. The researchers examined 100,000-year cycles of glaciation and interglaciation. They found that during colder and wetter periods, the increased flow of water and sediments cut deep slits in the valley. The basins filled back up with sediment during drier, warmer periods. Nearby river channels closer to the mountains responded similarly, but over cycles of 21,000 years.

These studies could offer clues about what parts of the landscape will be

\section{MATERIALS MAESTRO}

A computational physicist delves into the complex structures of organic materials.

Due to their abundance and low cost, organic molecules make excellent building blocks for flexible nanoelectronic devices. But achieving the properties needed to replace inorganic semiconductors, such as silicon, demands an intimate understanding of how the molecules interact at the nanoscale.

Sahar Sharifzadeh employs computational modelling to find intuitive ways of describing these molecular interactions, which could facilitate the development of organic materials whose electrical conductivity can be controlled with exquisite precision - a characteristic of semiconductors.

Sharifzadeh has used this theoretical approach to show that the arrangement of molecules in an organic crystalline material strongly influences how it responds electronically to light - an insight that could improve the efficiency and longevity of organic solar cells. Her computational analyses have also been applied to understanding the structures of promising inorganic materials.

In 2017, she simulated free-standing,

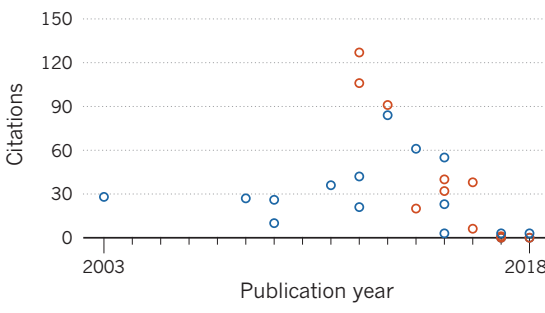

sensitive to the sudden changes in climate we are experiencing, says Schildgen. The results have "big implications for things like flood hazards and water management," she says.

Occasionally, Schildgen's work takes her further back in time. In July 2018, she coauthored a paper in Nature, refuting assumptions about the link between global climate and erosion. She established that there was insufficient evidence to suggest that the onset of glacial-interglacial cycles several million years ago accelerated erosion in alpine regions.

Schildgen traces her fascination for rocks back to a vacation to Yellowstone National Park as a teenager. After completing her $\mathrm{PhD}$ in geology at MIT in 2008, she took a postdoctoral position in Germany due to the shortage of academic positions in the United States. "Part of me feels guilt for having left the US because I received such good training there," she says. "But the reality of my situation is that I have been extremely well supported in Germany." SMRITI MALLAPATY 
one-atom-thick sheets of boron, known as borophene. Researchers have only recently grown the two-dimensional material on silver, but have not been able to isolate it in its freestanding form. Like its close relative graphene, borophene promises exceptional properties, including strength, flexibility and electrical conductivity. Sharifzadeh's calculations predict that borophene's optical and electronic properties could be precisely adjusted by stretching or compressing the material.

Sharifzadeh, whose family moved to the United States from Iran when she was eight, started out studying electrical engineering and computer science at the University of California, Berkeley, but the physics courses she took in that degree captured her imagination. Her PhD on condensed matter physics at Princeton University led to a two-year post-doctoral project on nanoscale materials at the US Department of Energy's Lawrence Berkeley National Laboratory in California. She set up her lab at Boston University in 2014.

She is modelling not just the behaviour of molecules, but that of the high-achieving scientist who is also the mother of a one-year-old. Aware that many young women fear the two roles are incompatible, she's happy to be seen doing both. CA

\section{MOTION TRACKER}

\section{A biophysicist develops microscopes} to peer into living tissue samples.

As a summer intern at the private foundation Brain and Spine Institute (ICM) in Paris, Olivier Thouvenin helped develop an imaging technique for monitoring the neural circuitry in zebrafish larvae. But the method lacked the spatial resolution to tease apart connections between neurons at the single-cell level, which frustrated the young biophysics master's student.

So for his $\mathrm{PhD}$ at the Langevin Institute - two kilometres away on the edge of Paris's famed Botanical Gardens - Thouvenin worked on improving an existing high-resolution tissue-imaging tool called full-field optical coherence tomography (OCT). He added a dynamic time element to the otherwise static picture-taker, and with that, Thouvenin says, "we could see things that were moving inside the sample". Thouvenin used his upgraded OCT technique to track the movement and metabolism of subcellular organelles and other structures inside living retina tissue from mice and monkeys.

Last year, he returned to the same ICM lab as a postdoc, with the microscope he'd designed in tow. Working with neuroscientist, Claire Wyart, he showed in

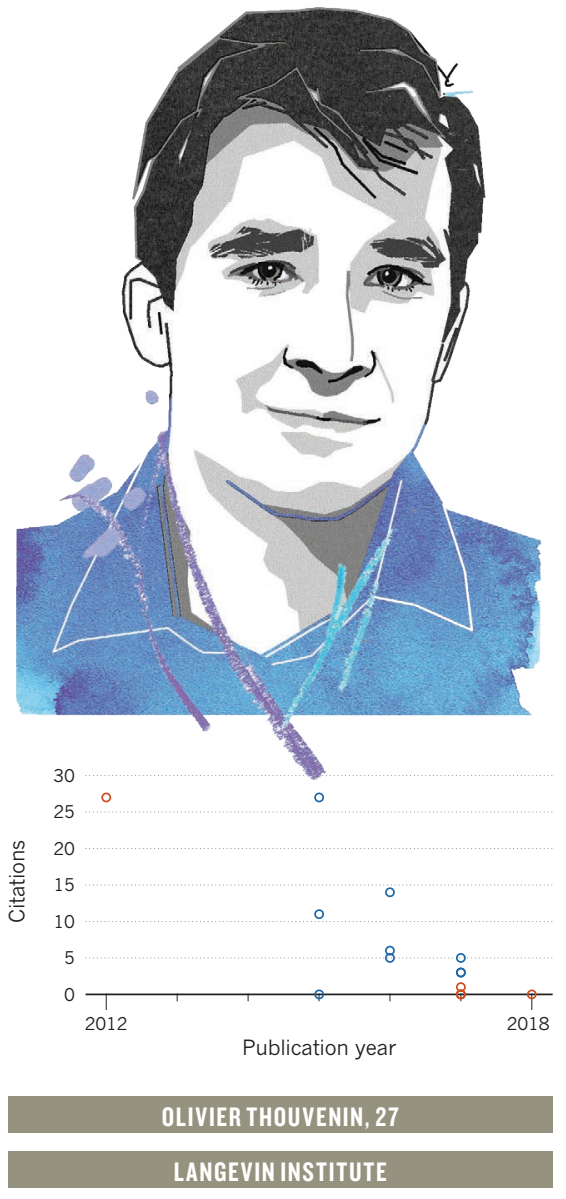

as-yet-unpublished research that cerebrospinal fluid in zebrafish larvae moves in both directions through the backbone, as in humans. Flow disturbance could result in spinal curvature defects, in fish and people.

About to start his own lab back at the Langevin Institute, Thouvenin is also thinking about how to make a bigger societal impact through research. "He's a very generous and open-minded person," Wyart remarks. Currently, most commercial OCT instruments used for diagnosing eye diseases and other health problems cost $€ 30,000$ (US\$34,800) or more, which makes them inaccessible for many hospitals in developing countries. Thouvenin hopes to bring the price down by using three-dimensional printing, cheap optical parts and a smartphone as a camera. "I'm building a prototype," he adds, one that should cost less than $€ 1,000$. ED

\section{FOREST MODELLER}

\section{An ecologist applies mathematical modelling to forest management.}

Giorgio Vacchiano started his career establishing the impact of climate change on forests, but is now finding ways of using forests to mitigate climate change.

His $\mathrm{PhD}$ thesis linked the high mortality of a hardy tree species in Italy's southwestern Alps to drought. The finding set the foundation for an influential paper, published in 2013, presenting strong evidence of the effects of climate change on forest coverage over a span of 20 years. A co-authored paper in Nature Climate Change in 2017 reviewed more than 600 studies and found overwhelming evidence of the role of climate change in the increasing frequency and magnitude of fires, droughts and pests.

Vacchiano's interest in conservation prompted him to study forestry, but he now believes in managing forests for multiple purposes. In Italy, he has pioneered the use of modelling for forest management. Using tools to simulate dynamics under different conditions allows estimation of, for example, how quickly trees will grow after a thinning, or how many trees are needed to stop rocks falling from a slope. These tools offer forest managers a more accurate and reproducible basis for decisions, he says. Vacchiano spent 15 months working on forest modelling with the European Commission before landing his current position at the University of Milan in 2017. He considers himself lucky. "There are a lot of brilliant young researchers who can't find research work in this country."

Vacchiano's current research focusses on optimizing forest management to mitigate climate change, including harvesting timber to replace more carbon-intensive materials such as concrete for building and fossil fuels for energy. CA $\mathbf{~}$

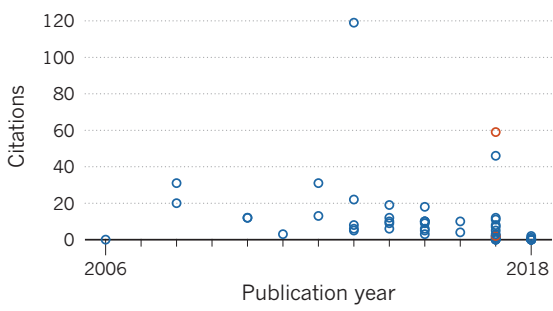

\section{GIORGIO VACCHIANO, 38}

UNIVERSITY OF MILAN
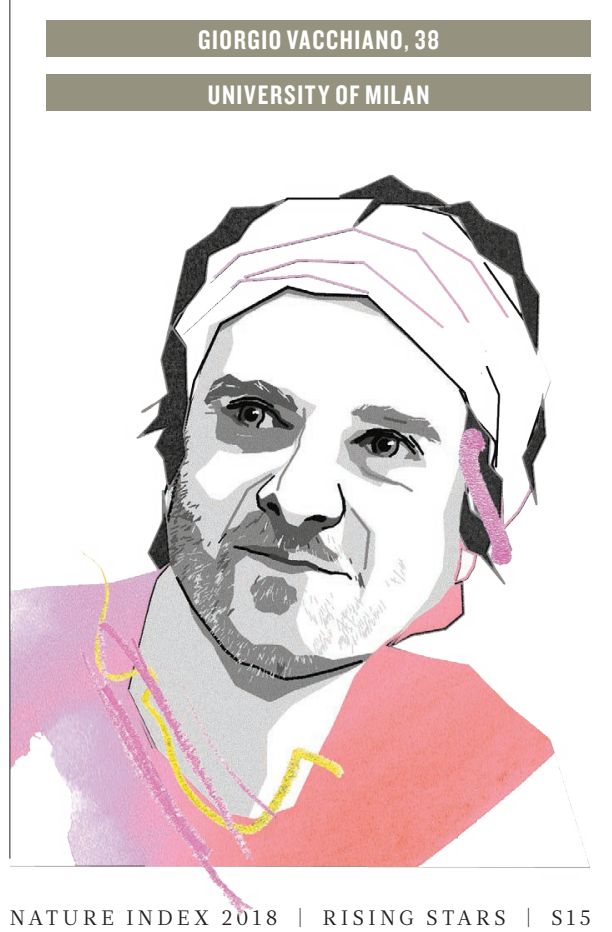